\title{
A categoria de voz em Tupí ${ }^{1}$
}

\author{
Aryon Dall'Igna Rodrigues
}

As categorias gramaticais que conhecemos nas modernas línguas indo-europeias nem sempre correspondem às que poderemos encontrar em línguas de outras famílias. Certas categorias que para nós parecem imprescindíveis, como, v. g., as de gênero e de número, ou, mais ainda, a de tempo, não se encontram em muitas línguas; por outro lado, ocorrem frequentemente categorias que desconhecemos e das quais jamais sentimos necessidade. $\mathrm{O}$ fato, porém, de cada língua possuir ou não determinada categoria, não indica, absolutamente, que seja esta língua mais ou menos rica. Dizemos que em tal língua existe uma categoria gramatical, quando ela se manifesta por um morfema qualquer; se não é acusada por nenhum elemento gramatical, a categoria não existe. Isso se dá no português, p. ex., com relação à categoria de aspecto (que é a maneira por que se apresenta a ação indicada pelo verbo, independentemente da noção de tempo). Entretanto, a noção correspondente não deixa de existir, e se revela sob formas diversas, quando se faz mister, embora independente de um sistema mórfico determinado; assim temos três verbos distintos exprimindo três aspectos de uma mesma ação: partir, andar, chegar

1. Servimo-nos da designação voz ativa para distinguir as formas que denotam simplesmente que o sujeito é o agente, sem fazer alusão a quaisquer outros acidentes, exclusivamente em atenção à tradição gramatical, uma vez que todas as demais vozes que encontramos em Tupí são também ativas, pois que nelas todas o sujeito é agente. Também a designação voz média é empregada somente por analogia à gramática indo-europeia. A grafia que aqui empregamos para as palavras tupís pouco difere da que é usada na Cadeira de Etnografia e Língua Tupí-Guaraní da Faculdade de Filosofia, Ciências e Letras de S. Paulo. Y é a vogal velar, não arredondada, característica do Tupí-Guaraní; $j$ é $i$ semiconsoante (i em ioiô); $m b$, nde, ng. oclusivas sonoras, labial, dental e velar, nasalizadas; $s$, fricativa dental surda $(c) ; x$ fricativa palatal surda $(c h) ; \tilde{n}$, naso-palatal $(n h)$. 
(aspectos inceptivo, durativo e terminativo, respectivamente). Existindo a noção, a categoria está, por assim dizer, latente, e pode vir a se manifestar por meio de determinados morfemas em cada fase da evolução da língua. Igualmente, desaparecendo por qualquer motivo os morfemas especializados, pode a categoria gramatical desaparecer; e isso não significará, de modo algum, que a língua tenha sofrido um retrocesso. Esse é o caso do inglês moderno, onde, em virtude da queda das terminações, ocasionada por um fator fonético, desapareceu praticamente a categoria de gênero, exclusivamente gramatical no velho inglês. No sentir de alguns linguistas, isso constituiu grande progresso linguístico, uma vez que a categoria gramatical cedeu à categoria nocional (de sexo), muito mais própria da mentalidade europeia moderna.

A categoria de voz, que em português conhecemos por apenas três modalidades manifestas morficamente (ativa, passiva e reflexiva), pode em outras línguas apresentar-se sob modalidades novas, determinadas por morfemas especializados, na conjugação verbal. Não necessário irmos muito longe para exemplificar isso: o grego clássico nos apresenta a voz média, que, se às vezes tem o mesmo valor da nossa voz reflexiva, representa ainda dois outros valores - a média dinâmica (hépomai = lat. sequor) e a média recíproca (máchontai $=$ lat luctantur).

A voz é, na definição de Marouzeau, "um aspect du verbe, défini par le rôle qu'on attribue au sujet, suivant qu'il accomplit l'action (actif), qu'il la subit (passif), qu'il y est intéressé d'une certaine maniére (moyen), etc." (Lexique de la Terminologie Linguistique, $2^{\text {a }}$ ed., Paris, 1943). Alguns autores dilatam mais o conceito de voz, relacionando-o a outros seres interessados no processo verbal, além do sujeito; esses outros seres são os complementos (objetos, adjunto causa eficiente, etc.).

No Tupí antigo, que é a língua que foi falada, nos séculos XVI, XVII e XVIII, pela tribos Tupí-Guaranís que habitavam no litoral brasileiro, do Rio de Janeiro para o Norte (Tupí, Tupinambá, Tupiniquim, Tobajara, Tamoio, Maracajá, Caeté, Temiminó, Pitiguara, etc.), e da qual nos deixaram gramáticas os missionários jesuítas José de Anchieta e Luís de Figueira, distinguimos sete vozes sistematizadas no processo de conjugação verbal.

Em primeiro lugar cumpre assinalar a voz ativa, em que o sujeito é simplesmente agente da ação indicada pelo verbo. Esta voz caracteriza-se pela ausência de morfema especial (morfema zero). Consiste na forma simples do verbo, conjugada com os pronomes, com os determinantes de aspectos e com os complementos diversos. Exs.: a-jukámbarakajá, "eu matei um maracajá", onde $a$ é o sujeito, jukáo tema verbal, mbarakajáo objeto direto, paciente; $a$ s-epiák, "eu o vi" (s-, objeto direto, "ele, o"; epiák, tema verbal); ja-kér, "nós todos dormimos"; Pedro o-i-potár xe kisé, "Pedro ele a quer minha faca", i. é, 
"Pedro quer minha faca" ( $o$, pronome sujeito; $i$, objeto direto pleonástico; $x e$ kisé, objeto direto); etc.

À voz ativa pertencem tanto verbos transitivos (a-jukámbarakajá), como intransitivos (a-kér).

$\mathrm{Na}$ voz causativa o sujeito faz outrem praticar a ação, em vez de ele mesmo praticá-la. Há, por conseguinte, dois agentes: um imediato, que pratica a ação (Untersubjekt dos gramáticos alemães) outro mediato, que faz aquele praticá-la, e que é o sujeito (Obersubjekt). Em português é obtida por meio do auxiliar fazer: fazer estudar, fazer comprar, etc. Um exemplo da voz causativa, com morfema especial, temos em latim: sto, "estou em pé"; si-sto, "faço estar em pé”. Em Tupí há três tipos de voz causativa: causativo-comitativa, causativo prepositivo e causativa propriamente dita. A voz causativa propriamente dita é formada sobre os verbos intransitivos, por meio do morfema mo-, mbo-, prefixo: ativo in, "estar": causativo mo-ín, "fazer estar, por"; at. jebyr, "voltar": caus. mo-jebyr, "fazer voltar"; at. úr, "vir": caus. mbo-úr, fazer vir, fazer com que venha"; at. iké, "entrar": caus. mo-ingé (por mõ-ikê), "fazer entrar, introduzir"; at. puám, "levantar-se": caus. mo-puám, "levantar (fazer levantar-se)"; at. sém, "sair": caus. mo-sém, "fazer sair, expulsar ou expelir"; etc. Exs.: a-i-mo-ndó Pedro, "eu o fiz ir Pedro", i. é, "fiz Pedro ir, enviei Pedro", a-i-mo-sém pajé xe-rókasuí, "eu o fiz sair o pajé minha casa de", i. é, "expulsei o pajé de minha casa”.

O verbo intransitivo na voz causativa passa a ser transitivo.

Na voz causativo-prepositiva, formada sobre os verbos transitivos, por meio do sufixo -ukár, o sujeito faz com que alguém pratique a ação sobre outrem: $a-i-k o t u ́ k-u k a ́ r$, "fiz com que alguém o ferisse, ou com que o ferissem". Na voz causativa propriamente dita, formada com o prefixo mo-, mbo-, há apenas dois seres interessados no processo verbal, enquanto que na causativo-prepositiva são três os seres interessados: o agente mediato, o agente imediato e o objeto. O agente imediato, que é um preposto do sujeito, é regido pela posposição supé: a-juká-ukár jagwára Pedro supé, "fiz com que Pedro matasse uma onça" ("matei uma onça, servindo-me de Pedro"), a-i-moñáng-ukár' Pedro supé, "faço com que Pedro o faça" "faço com que Pedro faça isso".

A causativo-prepositiva pode ser construída sobre um verbo já causativo, porquanto este é transitivo: a-i-mo-ndó-ukár, "faço que alguém o faça ir", "faço que alguém o envie" (causativo simples: a-i-mo-ndó, "faço-o ir por mim mesmo", "envio-o eu mesmo").

Na voz causativo-comitativa o sujeito faz outrem exercer a ação, praticando-a ele também; portanto, o sujeito e o complemento praticam a ação conjuntamente, em companhia, sendo ambos agentes imediatos. É esta voz denunciada pelo morfema ro, prefixo: at. puám, "levanta-se: caus.-com. ro- 
-puám, "fazer levantar-se consigo"; at. manó, "morrer": caus.-com. ro-manó, "fazer morrer consigo"; at. ikó, "estar": caus. mo-ingó (por mõ-ikó), "fazer estar, por": caus.-com. rekó (por ro-ikó), "fazer estar consigo, ter"; at. só, "ir": caus. mo-ndó (por mõ-só), "fazer ir, enviar": caus.-com. ra-só (por ro-só), "fazer ir consigo, levar"; at. úr, "vir": caus. mbo-úr, "fazer vir": caus.-com. r-úr (por ro-úr), "fazer vir consigo, trazer"; etc. Exs: a-ro-kér xe ray'ra, "eu faço dormir comigo o meu filho", ou, na tradução de Anchieta, "durmo eu, e meu filho também dorme"; pe-r-úr pe mbaé, "vós fizestes vir convosco as vossas coisas", i. é, "trouxestes as vossas coisas".

Na voz média o sujeito é especialmente interessado na ação. No Tupí temos três modalidades de média: média reflexiva, média recíproca e média propriamente dita. A voz média reflexiva é aquela em que o sujeito pratica a ação sobre si mesmo, sendo, simultaneamente, agente e paciente, como no lat. lauor = port. lavome. Esta voz é formada pelo morfema je-, ñe-prefixado ao tema verbal: at. juká, "matar": reflexivo je-juká, "matar-se, suicidar-se"; at. kotúk, "ferir": refl. je-kotúk, "ferir-se"; at. sók, "picar": refl. je-sók, "picar-se"; at. moapuã, "tornar redondo": refl. ñe-moapuã, "tornar-se redondo"; etc.

$\mathrm{Na}$ voz média recíproca os sujeitos (plural) praticam a ação uns sobre os outros, mutuamente. É o caso do port. desafiar-se ou do lat. luctari, gr. Máchesthai. O morfema da voz média recíproca é jo-, ño-, prefixado ao tema verbal justamente como je-, ñe- da voz reflexiva: at. juká, "matar": recíproco jo-juká, "matarem-se mutuamente"; at. kotúk, "ferir": rec. jo-kotúk, "ferirem-se mutuamente"; at. sók, "picar": rec. jo-sók, "picarem-se uns aos outros"; at. nupã, "açoutar": rec. ño-nupã, "açoutarem-se reciprocamente”; etc. Exs.: refl. pe-je-kotúk, "vós vos feris (cada um a si mesmo)": rec. pe-jo-kotúk, "vós vos feris reciprocamente"; refl. tapyy’ja o-je-juká, "os índios suicidaram-se": rec. tapyy’jao-jo-juká, os "índios mataram-se uns aos outros”; refl. oró-ñe-nupã, "nós outro nos açoutamos (cada um a si mesmo)" rec. oró-ño-nupã, "nós outros nos açoutamos (uns aos outros)"; etc.

A voz média propriamente dita é aquela em que o sujeito pratica a ação para si, em seu benefício. É a média do grego e sânscrito thyetai, "ele sacrifica para si”. Em Tupí esta voz é indicada pelo mesmo morfema jo-, ño-, agora, porém, prefixado não ao tema verbal, mas à posposição que a este convier, ficando como que infixado entre esta e o pronome pessoal regido. Assim: $a-$ -i-monhyrõ Tupãxe-jo-upé, “aplaco a Deus para mim”; ndé e-i-monhyrõ Tupã nde-jo-upé, "aplaca tu a Deus para ti", lit. "tu tu o aplaca, Deus tu-mesmo-para”; aTupã mongetáxe-jo-esé, "eu rogo a Deus por mim”; Pedro t-o-i-mongetá o-jo-esé, "Pedro rogue-lhe por si", lit. "Pedro que ele lhe rogue ele-mesmo-por". Compare-se uma oração na voz ativa: $e$-i-monhyrõ Tupãixébe, "(tu) aplaca a Deus para mim", ou a-i-monhyrõ Tupã ndébe, "aplaco a Deus para ti" (ixébe e ndêbe, dativos de ixé, "eu", e ndé, "tu”). 
Com o emprego simultâneo do prefixo je-, ñe- da voz reflexiva e do sufixo -ukárda causativo-prepositiva, é obtida ainda uma forma causativo-reflexiva, indicando que o sujeito faz com que alguém pratique a ação sobre ele mesmo: a-je-juká-ukár Pedro supé, "faço com que Pedro me mate" ("mato-me servindo-me de Pedro"); a-je-apín-ukár xe rúba supé, fiz-me tosquiar por meu pai", "fiz que meu pai me tosquiasse"; o-ñe-nupã-ukár osy' supé, "fez com que sua mãe o surrasse", "fez-se surrar por sua mãe". 